Oral Section

\title{
Experimental evidence in support of the biological effects and physical basis of homeopathic potencies
}

\author{
Nirmal Chandra Sukul \\ Department of Botany, Visva-Bharati University, Santiniketan-731235, West Bengal, India
}

\begin{abstract}
Background: Homeopathic potencies $12 \mathrm{cH}$ and above cross the Avogadro number and, for this, do not contain any original drug molecules. Two major problems involved in the scientific study of potencies are (1) understanding the physical basis of potencies and (2) demonstrating the biological effects of potencies. The present study aims to address these questions.
\end{abstract}

Methods and Results: In course of our experimental studies spanned over more than 30 years we have demonstrated significant effects of homeopathic potencies on man, animals and plants. We have also showed that potencies could be differentiated through their electronic spectra, and this difference in spectra can be attributed to the electron transfer interaction. In a molecular complex, electron of one molecule absorbs a quantum of visible radiation and is excited, not to a higher energy level of this molecule, but to one of the vacant high energy levels of the neighboring molecules. This process is known as electron or charge transfer interaction. This has been demonstrated in Iodine $\theta$ in two different solvents of $\mathrm{CCl}_{4}$ and aqueous ethanol (Sukul N C, Environ Ecol 17,866-872, 1999).

We have further demonstrated that the effect of a homeopathic potency can be transmitted from one part of a plant to another, and also from one plant to another through water. I am presenting here a few selected cases of our experimental studies. Potentized Nux vomica significantly reduced ethanol consumption in rats by 73.7\%and ethanol-induced sleep time in albino mice by $44.4 \%$. Causticum $30 \mathrm{C}$ and Rhus tox $30 \mathrm{C}$ produced anti-inflamatory and anti-nocicptive effect on adjuvant arthritis in albino rats. Potentized homeopathic drugs reduced microfilaraemia by 28 to $100 \%$ and filariasis in two villages of West Bengal endemic for Bancroftian filaiasis. Potentized Cina and Thuja ameliorated trichinellosis in mice reducing larval population in muscles by $84 \%$ and $68 \%$, respectively.

Potencies of Agaricus and Nux vomica, produced excitatory effect on the isolated rat ileum. Potentized drugs altered firing rate of hypothalamic neurons in rats and cats. Nux vom $30 \mathrm{c}$ and Merc cor 30c facilitated water permeability in erythrocytes of catfish in a test tube. Potencies of Merc cor and Merc iod enhanced $\alpha$-amylase activity in vitro ,by 44 and $21 \%$,respectively.

Drugs that inhibit photosynthesis and plant growth in high doses, promote the same phenomena when applied on plants at ultra low doses. Potentized Cantharis, a homeopathic drug used for burn injuries, counter the effect of heat shock in Adhatoda vasica plants in terms of modulating the expression of heat-shock proteins in the plants. The effect of heat shock and of Cantharis treatment could be transmitted from one plant to another through water. The global network of surface water in a closed system is thought to be responsible for producing this effect. 
Several potentized homeopathic drugs show distinct variation from each other in their absorption spectra in ultra violet region of light. These drugs when mixed with sucrose solution, also show marked differences from each other at temperatures as low as $4{ }^{\circ} \mathrm{C}$ and as high as $70^{\circ} \mathrm{C}$. Electron transfer interaction may contribute to the characteristic spectral properties of a homeopathic potency.

Conclusions: Homeopathic potencies could be detected and differentiated by their electronic spectra. Potencies show marked effect on animals, plants, ex vivo effect on isolated organs and in vitro effect on enzymes.

Keywords: Homeopathic potencies, electronic spectra, ethanol intake, adjuvant arthritis, filariasis, Cantharis, Nux vomica

\section{(c)) BY-NC-ND Licensed to GIRI}

Support: University Grant Commission (UGC), Central Council for Research in Homeopathy(CCRH), The Asiatic Society Conflict of interest: authors declare there is no conflict of interest

Received: 01 June 2012; Revised: 08 August 2012; Published: 30 September 2012.

Correspondence author: Nirmal Chandra Sukul, ncsukul@gmail.com

How to cite this article: Sukul NC. Experimental evidence in support of the biological effects and physical basis of homeopathic potencies. Int J High Dilution Res [online]. 2012 [cited YYYY Month dd]; 11(40):142-143. Proceedings of the XXVI GIRI Symposium; 2012 Sep 20-22; Florence (Italy). GIRI; 2012; Available from: http://www.feg.unesp.br/ ojs/index.php/ijhdr/article/view/568/580 